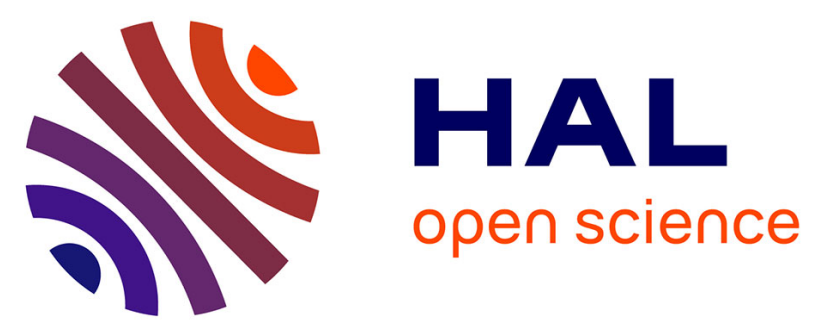

\title{
Forming nacreous layer of the shells of the bivalves Atrina rigida and Pinctada margaritifera: An environmental- and cryo-scanning electron microscopy study
}

Fabio Nudelman, Eyal Shimoni, Eugenia Klein, Marthe Rousseau, Xavier

Bourrat, Evelyne Lopez, Lia Addadi, Steve Weiner

\section{To cite this version:}

Fabio Nudelman, Eyal Shimoni, Eugenia Klein, Marthe Rousseau, Xavier Bourrat, et al.. Forming nacreous layer of the shells of the bivalves Atrina rigida and Pinctada margaritifera: An environmentaland cryo-scanning electron microscopy study. Journal of Structural Biology, 2008, 162, pp.290-300. 10.1016/j.jsb.2008.01.008 . insu-00287022

\section{HAL Id: insu-00287022}

\section{https://hal-insu.archives-ouvertes.fr/insu-00287022}

Submitted on 10 Jun 2008

HAL is a multi-disciplinary open access archive for the deposit and dissemination of scientific research documents, whether they are published or not. The documents may come from teaching and research institutions in France or abroad, or from public or private research centers.
L'archive ouverte pluridisciplinaire HAL, est destinée au dépôt et à la diffusion de documents scientifiques de niveau recherche, publiés ou non, émanant des établissements d'enseignement et de recherche français ou étrangers, des laboratoires publics ou privés. 


\title{
Forming nacreous layer of the shells of the bivalves Atrina rigida and Pinctada margaritifera: An environmental- and cryo-scanning electron microscopy study
}

\author{
Fabio Nudelman ${ }^{a}$, Eyal Shimoni ${ }^{b}$, Eugenia Klein ${ }^{b}$, Marthe Rousseau ${ }^{c}$, Xavier Bourrat ${ }^{d}$, \\ Evelyne Lopez ${ }^{c}$, Lia Addadi ${ }^{\mathrm{a}}$ and Steve Weiner ${ }^{\mathrm{a}}$ \\ ${ }^{\mathrm{a}}$ Department of Structural Biology, Weizmann Institute of Science, Rehovot 76100, Israel \\ ${ }^{\mathrm{b}}$ Department of Chemical Research Support, Weizmann Institute of Science, Rehovot 76100 , \\ Israel
}

${ }^{\mathrm{c}}$ Muséum National d'Histoire Naturelle, Départment des Milieux et Peuplements Aquatiques UMR 5178 : CNRS-MNHN : Biologie des Organismes Marins et Ecosystemes 43, rue Cuvier CP26, 75005 Paris, France

${ }^{\mathrm{d}}$ Institut des Sciences de la Terre d'Orleans, CNRS-Université d'Orleans, 1A, rue de la Ferollerie, 45071 Orleans cedex 2, France

\begin{abstract}
A key to understanding control over mineral formation in mollusk shells is the microenvironment inside the pre-formed 3-dimensional organic matrix framework where mineral forms. Much of what is known about nacre formation is from observations of the mature tissue. Although these studies have elucidated several important aspects of this process, the structure of the organic matrix and the microenvironment where the crystal nucleates and grows are very difficult to infer from observations of the mature nacre. Here, we use environmental- and cryo-scanning electron microscopy to investigate the organic matrix structure at the onset of mineralization in the nacre of two mollusk species: the bivalves Atrina rigida and Pinctada margaritifera. These two techniques allow the visualization of hydrated biological materials coupled with the preservation of the organic matrix close to physiological conditions. We identified a hydrated gel-like protein phase filling the space between two interlamellar sheets prior to mineral formation. The results are consistent with this phase being the silk-like proteins, and show that mineral formation does not occur in an aqueous solution, but in a hydrated gel-like medium. As the tablets grow, the silk-fibroin is pushed aside and becomes sandwiched between the mineral and the chitin layer.
\end{abstract}

Keywords: Biomineralization; Mollusk shell nacre; Matrix macromolecules; Cryo-scanning electron microscopy; Silk fibroin

\section{Introduction}

The nacreous layer, or "mother-of-pearl", is the innermost layer of many mollusk shells. It is widely studied as a model for understanding biomineralization processes, because of its regular brick wall-like structure. It is composed of polygonal aragonite crystals that are 5$15 \mu \mathrm{m}$ in diameter. They are arranged in continuous parallel laminae around $0.5 \mu \mathrm{m}$ thick, separated by sheets of interlamellar organic matrix ([Gregoire, 1957], [Watabe, 1965] and 
[Wise, 1970]). Nacre tablets are single crystals with a sub-structure composed of 30-50 nm domains embedded in organic material (Rousseau et al., 2005b). TEM studies of the growing nacre have demonstrated that the interlamellar matrix is formed prior to mineral deposition (Bevelander and Nakahara, 1969) and that in the mature nacre it is composed of an electron lucent layer enclosed by two electron dense layers (Nakahara, 1979). The major component of the interlamellar matrix is $\beta$-chitin (Levi-Kalisman et al., 2001), whose fibrils are preferably aligned in a direction parallel to the $a$-axis of the juxtaposed crystals, indicating that the crystal orientation upon nucleation is governed, either directly or indirectly, by chitin (Weiner and Traub, 1984). Levi-Kalisman et al. (2001) were not able to image the other major components of the matrix, the silk-like proteins ([Weiner et al., 1983] and [Weiner and Traub, 1980]), and suggested that they are present in a hydrated gel-like state filling the space between two layers of chitin prior to mineral formation. Although preliminary results supporting this hypothesis were provided from experiments on mature shells (Addadi et al., 2006), the involvement of a gel phase in the forming stages still remains to be demonstrated. An assemblage of relatively soluble macromolecules forms a third class of macromolecules. Many of these are glycoproteins rich in aspartic acid ([Crenshaw, 1972] and [Weiner, 1979]). Some of these proteins are adsorbed on the chitin scaffold and constitute the nucleation site of the forming tablet ([Crenshaw and Ristedt, 1976] and [Nudelman et al., 2006]). In addition, some are able to specifically nucleate aragonite ([Belcher et al., 1996] and [Falini et al., 1996]). Another group of the aspartic acid-rich proteins are located within the mineral phase ([Berman et al., 1993] and [Weiner and Addadi, 1997]). Although $\beta$-chitin, the silk-like proteins and the acidic proteins are considered the major components of the organic matrix of the nacre, several other proteins have been identified and characterized over the past 10 years for a review on mollusk shell proteins see Marin and Luquet (2004).

The zone between the mantle and the shell is of much importance for the understanding of shell formation. This zone is filled with the extrapallial fluid, into which it is often assumed that the matrix macromolecules and the ions necessary for mineralization are secreted by the mantle cells (Bevelander and Nakahara, 1969). It has been subsequently surmised that the macromolecules self-assemble in the extrapallial fluid to form the organic matrix and later mineralization occurs. It is more likely, however, that the mantle cells are juxtaposed to the mineralizing matrix where and when shell is produced (Simkiss and Wilbur, 1989).

Furthermore, a viscous fluid in the space where the nacre tablets form between the mantle cells and the nacre surface, was reported (Rousseau et al., 2005a). A fibrous thin organic film adhering to the growing mineral surface was also observed in some mollusk species, and in many cases it contained associated particles and possibly crystals ([Neff, 1972] and [Waller, 1980]). In the shell of Mercenaria mercenaria, this layer is observed immediately above the microvilli of the mantle epithelium (Neff, 1972). The composition of this film and its functional significance are not known.

The mechanisms of mineral transport to the mineralization site are also an important issue in shell formation. Observations of mineral-containing granules within the mantle epithelial cells suggest that calcium carbonate is not transported in solution, but as an already formed mineral phase (Neff, 1972). The nature of the first deposited mineral phase in nacre-whether crystalline or not - is not clear. Weiss et al. (2002) showed that in mollusk larvae, the firstformed mineral phase is amorphous calcium carbonate (ACC), which subsequently transforms into aragonite. Echinoderms and sponges are also known to use an ACC precursor phase to form their skeletons and spicules ([Politi et al., 2004] and [Sethmann et al., 2006]). Although it is not known whether the same strategy is used in nacre formation, there is some indirect evidence that this might be the case. The mineral containing granules observed by Neff (1972) 
did not produce electron diffraction patterns, and therefore could be composed of ACC. Nassif et al. (2005) have shown that nacreous tablets of adult mollusk shells are coated by a thin layer of ACC, suggesting that this phase is present in nacre.

The microenvironment formed by the 3-dimensional organic matrix framework is critical for proper regulation over mineral formation. Much of what is known to date about nacre formation comes from studies of the mature tissue. Although these studies have been extremely important, this approach is rather limited as it involves investigating the fully formed layer in order to understand its process of formation. In particular, the structure of the organic matrix and the microenvironment where the crystal nucleates and grows are very difficult to infer from observations of the mature nacre. Hence, the study of a mineralized tissue during its formation process is essential. This however is not trivial, and requires the use of appropriate methodologies.

Here, we employed environmental scanning electron microscopy (ESEM) and cryo-scanning electron microscopy (cryo-SEM) in order to investigate the space between two interlamellar sheets, namely the site where the mineral forms, in the nacre of two mollusk species: the stiff pen shell Atrina rigida and the black-lip pearl oyster Pinctada margaritifera. ESEM and cryoSEM are two techniques that allow direct observation of hydrated biological materials while avoiding demineralization. Cryo-SEM involves the fast-freezing of a sample, exposure of a new fracture surface and microscopic observation at $-120^{\circ} \mathrm{C}$. This procedure results in the organic matrix structure being preserved in close to physiological conditions. It is thus suitable for the study of the organic matrix structure at the growth front and for determining the spatial relationships between the matrix and the growing and mature nacre tablets. In the present study, we confirm the model proposed by Levi-Kalisman et al. (2001), showing that the silk-like proteins are present in a hydrogel state, and significantly expand our current knowledge of the dynamics of the nacre tablet formation in relation to the organic phase.

\section{Materials and methods}

\subsection{Materials}

Atrina rigida (A. rigida) specimens were caught alive on the east coast of Florida and were immediately frozen in liquid nitrogen by Gulf Specimen Marine Laboratories Inc (Panacea, FL, USA) and stored at $-20{ }^{\circ} \mathrm{C}$ until removal of the animal, after which they were stored dry at $4{ }^{\circ} \mathrm{C}$. Fragments from the nacreous layer were mechanically separated from the prismatic layer at the pallial line and extensively washed with Milli-Q water prior to sample preparation for electron microscopy.

Pinctada margaritifera (P. margaritifera) specimens were caught alive in French Polynesia, immediately fixed in $4 \%$ formaldehyde and $0.5 \%$ cetylpyridinium chloride $(\mathrm{CPC})$ and stored in fixative solution at room temperature. Before preparation for scanning electron microscopy the outer prismatic layer was removed by manual polishing and the fragments were washed extensively with Milli-Q water.

\subsection{Enzymatic treatments}

Unfixed nacre samples from the shell of $A$. rigida and fixed ones from the shell of $P$. margaritifera were subjected to chitinase or protease. Fragments were incubated with $0.2 \mathrm{U}$ of chitinase from Streptomyces griseus (Sigma) in $0.05 \mathrm{M}$ phosphate buffer $\mathrm{pH} 6.3$ at room 
temperature for $16 \mathrm{~h}$ with shaking. For protease, samples were incubated with proteinase $\mathrm{K}$ (Sigma) in phosphate-buffered saline (PBS, Sigma) at room temperature for $48 \mathrm{~h}$, and every $12 \mathrm{~h} 40 \mu \mathrm{g}$ of enzyme was added, to a total of $160 \mu \mathrm{g}$.

\subsection{Conventional scanning electron microscopy}

Fragments of the nacre from the shell of $A$. rigida were fixed for $1 \mathrm{~h}$ with $4 \%$ formaldehyde and $0.5 \%$ cetylpyridinium chloride at room temperature, extensively washed with Milli-Q water and processed for electron microscopy (see below). Alternatively, nacre specimens from the shells of $A$. rigida and $P$. margaritifera were treated with $6 \%$ sodium hypochlorite for $5 \mathrm{~min}$ at room temperature with gentle shaking.

Samples were dehydrated in an ethanol series, $(50 \%, 70 \%, 96 \%$, and $100 \%)$, critical point dried using a CPD-030 critical point dryer (Bal-Tec, Liechtenstein), coated with $4 \mathrm{~nm}$ chromium in a K757X Chromium Sputterer (Emitech) and visualized in a high-resolution Ultra 55 SEM (Zeiss, Germany) using an in-lens immersed overnight in $10 \% \mathrm{NH}_{4} \mathrm{OH}$, extensively washed with Milli-Q water, fixed with $2 \%$ glutaraldehyde for $30 \mathrm{~min}$ at room temperature and washed with Milli-Q to remove the fixative. Fixed fragments of the nacre from the shell of $P$. margaritifera were extensively washed with Milli-Q water.

Fragments from both shells a few millimeters in size were mounted under water and examined in the environmental scanning electron microscope (ESEM) XL 30 ESEM FEG (Phillips/FEI) at $10 \mathrm{kV}$, using wet mode at $5^{\circ} \mathrm{C}$. Samples were observed as they slowly dried

at vapor pressure $\quad 6$ torr. As controls, ESEM observations secondary electron detector.

\subsection{Environmental scanning electron microscopy}

Fragments of the nacre from the shell of $A$. rigida were were also performed on samples pretreated with protease. In that case, nacre fragments were incubated with proteinase $\mathrm{K}$ as described above.

\subsection{Cryo-scanning electron microscopy}

Fragments of nacre from $P$. margaritifera were plunged into liquid ethane using a custom made spring-loaded plunger, were freeze-dried for $1 \mathrm{~h}$ at $-105^{\circ} \mathrm{C}$ in a BAF 60 freeze fracture device (Bal-Tec), coated with $3 \mathrm{~nm} \mathrm{Pt} / \mathrm{C}$ by double axis rotary shadowing and an additional layer of $1 \mathrm{~nm}$ carbon and transferred to the scanning electron microscope (see below). Alternatively, the samples were mounted in an aluminum platelet with a cavity of $200 \mu \mathrm{m}$ deep, filled with either $10 \%$ dextran (Fluka) or with 1-hexadecene (Sigma). The samples were then cryo-immobilized in an HPM 10 high pressure freezing device (Bal-Tec) and subsequently mounted on a holder and transferred to a BAF 60 FF device (Bal-Tec) using a VCT 100 Vacuum Cryo Transfer device (Bal-Tec). Frozen samples were fractured at a temperature of $-120^{\circ} \mathrm{C}$, etched for either 5 or $20 \mathrm{~min}$ at $-105^{\circ} \mathrm{C}$ at vacuum better than $5 \times 10^{-7}$ mbar and coated with $3 \mathrm{~nm} \mathrm{Pt} / \mathrm{C}$ by double axis rotary shadowing with an additional backing layer of $1 \mathrm{~nm}$ carbon evaporated perpendicularly. Samples were transferred to an Ultra 55 SEM (Zeiss, Germany) using a VCT 100 and were observed using a secondary electron and a backscattered electron in-lens detectors at a temperature of $-120{ }^{\circ} \mathrm{C}$. 


\section{Results}

\subsection{The nature of the outermost surface organic layer}

The inner surfaces of the $P$. margaritifera and A. rigida shells at the growth front are composed of numerous growing aragonite crystals that are barely visible, as they are covered by a sheet of organic material (Figs. $1 \mathrm{~A}$ and $\mathrm{E}$ ). Treatment with sodium hypochlorite removes the organic matrix and the growing crystals are clearly exposed (Figs. 1B and F). The terracelike mode of growth, characteristic of bivalves, is evident. Furthermore, it is interesting to note that while the growing aragonite crystals from the nacre of $P$. margaritifera are round, the ones from the nacre of $A$. rigida are polygonal in shape. These morphological differences may be either seasonal or intrinsic of each species (Wada, 1972).

The top layer of organic material on the inner shell surface may be nacre interlamellar matrix or a different material possibly derived from the mantle cells or from the interpallial or extrapallial fluids. It may also conceivably be an artifact of chemical fixation. To establish the nature of the outermost organic layer, we treated the samples with chitinase and protease. The top layer completely disappeared from the $P$. margaritifera samples after chitinase treatment (Fig. 1C), exposing the underlying mineral in a manner very similar to sodium hypochlorite treatment (Fig. 1B). The aragonite tablets from the nacre of $A$. rigida also became exposed after chitinase treatment, although the surface remained full of debris (Fig. 1G). After protease treatment, a dense network of fibers covering the growing crystals on the nacre of both species was evident (Figs. 1D and H). As the fibers are removed by treatment with chitinase, but not with protease, it is clear that they are composed of chitin. We thus conclude that the top layer of organic matrix covering the growing aragonite tablets contains both chitin in the form of fibrils and protein, and therefore closely resembles the interlamellar matrix.

\subsection{The state of the silk-like proteins in the interlamellar matrix}

The next question we address is whether the proposed presence of the silk-like proteins in a hydrated gel-like phase (Levi-Kalisman et al., 2001) as part of the interlamellar matrix, can be supported. Following a preliminary experiment (Addadi et al., 2006), nacre fragments were mounted under water and observed as they slowly dried at a water vapor pressure of 6 torr and $5{ }^{\circ} \mathrm{C}$. These conditions correspond to $92 \%$ humidity, which is just below the dew point of water $\left(6.4\right.$ torr at $\left.5{ }^{\circ} \mathrm{C}\right)$. Approximately $1 \mathrm{~h}$ elapsed between the mounting and the first image, where the nacre surface from $P$. margaritifera was still almost completely covered with water and the aragonitic tablets were barely visible (Fig. 2A). During this time, some material occluded between the mineral tablets leached out in the water, as was previously observed for A. rigida (Addadi et al., 2006). The pressure was maintained at 6 torr for $30 \mathrm{~min}$, and then successively lowered to 5.7 torr ( $87 \%$ humidity) for $30 \mathrm{~min}$ and to 5.3 torr ( $81 \%$ humidity) for $20 \mathrm{~min}$. Water evaporated very slowly and only a few aragonitic tablets were detectable beneath a heavily hydrated material (Fig. 2B). Finally, vapor pressure was further lowered to 4.7 torr ( $72 \%$ humidity) for 30 min until complete dryness. At this stage, a gel-like substance covering the aragonite crystals' surface was evident (Fig. 2C). Similar results were obtained from the mature nacre from the shell of A. rigida. After complete drying, the gel-like substance formed a film covering the tablets' edges (Figs. 2E-G).

Nacre fragments from the shell of $P$. margaritifera that were pre-treated with proteinase $\mathrm{K}$ and observed using the same procedure (Fig. 2D) showed very little gel-like material when compared to untreated fragments (Figs. 2A-C), while fragments from A. rigida shell were 
completely devoid of organic material (Figs. $2 \mathrm{H}$ ). Taken together, these observations indicate that the material that exudes from the nacre when it is exposed to water is composed of protein and behaves as a gel. Based on the data from Pereira-Mouries et al. (Pereira-Mouries et al., 2002), these are conceivably the silk-like proteins.

\subsection{The gel phase at the growing edge}

The identification of a hydrated gel-like material leaching out from the mature nacre raised the important question of its involvement in the mineral formation stages. For this purpose we used cryo-scanning electron microscopy (cryo-SEM). The sample preparation procedure involves sample embedding in a non-penetrating medium (dextran, 1-hexadecene) that operates as a filler and cryoprotectant. After high pressure freezing of the embedded sample, fresh fracture surfaces are exposed while the sample is frozen. A small amount of the ice is removed by sublimation in vacuum at $-105^{\circ} \mathrm{C}$ ("etching"), the frozen sample is coated with metal, transferred into the microscope and the frozen coated fracture surface is examined at $-120{ }^{\circ} \mathrm{C}$. This technique is essential for the visualization of hydrated biological materials, in particular gel-phases, as it does not involve dehydration of the sample, which would cause the gel to collapse. Rapid freezing ensures the preservation of the organic matrix structures at the growth front and their observation in a close to physiological conditions state. It also minimizes artifacts due to sample preparation.

Fig. 3 shows the fracture surfaces of nacre fragments from $P$. margaritifera using both secondary electron (left hand column) and backscattered electron (right hand column). The latter is useful for differentiating mineral (high contrast areas) from non-mineral (low contrast areas). Figs. 3A-B show a cross-section of the nacre embedded in dextran and etched for $5 \mathrm{~min}$. The mineral phase in this region is very rough and full of cavities, indicating that these layers are not fully formed. Two forming tablets are visible in the top layer of the nacre. The spaces surrounding the two tablets are filled with organic material, appearing as dark areas in the backscattered electron detector image (Fig. 3B, white arrows). Furthermore, the tablets in the underlying layers are not in direct contact with each other or with the underlying and overlying tablets, but are separated by organic material in the interlamellar space (Figs. 3A-B, white arrowheads). When the nacre fragments were etched for $20 \mathrm{~min}$, the organic material surrounding the tablets partially dried and acquired a network-like appearance (Fig. 3C-F). Note that the texture of the network does not reflect the original structure of the gel, and it may also be influenced by the presence of other solutes including salts. Empty spaces remained between the layers of tablets (Fig. 3C-D). In addition, the topmost interlamellar sheet that encloses the space where new tablets form and grow is now clearly visible (Figs. 3C and $\mathrm{E}$, white arrows). We also note that the observed profile of the matrix section may have been influenced by fixation. Figs. 3C-D show that the space between the topmost interlamellar matrix sheet and the next sheet is filled by a growing nacre tablet $\sim 0.13 \mu \mathrm{m}$ thick and $\sim 1.6 \mu \mathrm{m}$ wide, as well as by organic material. Interestingly, the growing tablet shown appears to adhere to the upper sheet of the interlamellar matrix and does not lie on the underlying nacre crystal. Figs. 3E-F shows another tablet growing in a space that is partially filled with a network-like organic material. This tablet is also attached to the interlamellar matrix (arrows) through its upper surface, and does not make contact with the underlying tablet. It is possible that these tablets grew off the top interlamellar sheet, or detached from the underlying matrix sheet during sample preparation. Furthermore, the growing tablet in Figs. 3E-F is very irregular with protruding edges. Since these edges are only approximately 200-300 nm apart, it is unlikely that they belong to different tablets, formed independently at such a short distance from each other. 
The dry, space-filling organic material we observed in the top layer has the same texture as the embedding dextran (marked as stars in Figs. 3A-F), making it difficult to be sure that this is not an artifact of the embedding process. We therefore also used 1-hexadecene as an alternative mounting medium for high-pressure freezing. After drying for $5 \mathrm{~min}$, we observed a space-filling organic material in the topmost layer of the nacre (Figs. 3G-H, white arrow). The texture of this material is very different from that of the 1-hexadecene (white star), demonstrating that it indeed belongs to the nacre organic matrix and is not an artifact of sample preparation. A growing tablet is visible, lying on the underlying mineral layer and covered by organic material (black arrowhead).

\subsection{Nacre tablet growth}

A comparison between the nacre tablets in the growing front (the 5 or so topmost layers) and those in the mature region (15-20 layers below the surface) can provide information on the process of tablet growth and organic matrix maturation during mollusk shell formation. In the growth front and immediately under it the tablets are very rough in texture and are interspaced by a thick layer of organic matrix (Fig. 3 and Fig. 4), whereas in the mature region the tablets are smooth and regular and are so close to each other (Figs. 4C-F) that the interlamellar sheets between the tablets are barely visible at this magnification. At this stage of growth we assume that most of the mineral phase of the tablet is crystalline aragonite. Furthermore, the drastic decrease in the thickness of the interlamellar matrix as the nacre tablets mature is accompanied by a significant increase in the tablet thickness (Figs. 4A and C). These differences are confirmed in the histograms showing the measured distributions of organic matrix (Fig. 5A) and tablet thicknesses (Fig. 5B). In the growing front, the organic matrix thicknesses ranged from 18 to $157 \mathrm{~nm}$, with an average of $68 \pm 29 \mathrm{~nm}$, while in the mature region they ranged from 11 to $25 \mathrm{~nm}$, with an average of $15 \pm 4 \mathrm{~nm}$. The tablet thicknesses in the growth front varied from 206 to $515 \mathrm{~nm}$, with an average of $350 \pm 73 \mathrm{~nm}$, while in the mature region they varied from 330 to $616 \mathrm{~nm}$, with an average of $460 \pm 68 \mathrm{~nm}$. In Figs. 4E$\mathrm{F}$, a transition region can be observed, where the interlamellar matrix separating the mineral layers can be observed only up to a certain depth in the shell (white arrowheads), after which the crystals are in very close contact with each other and no organic matrix is visible between them (white arrows). Moreover, all the tablets in this area have the same smooth texture as the mature ones shown in Figs. 4C-D.

A higher magnification view of a region of the growth front, etched for $20 \mathrm{~min}$, clearly shows the space between two nacre laminae and the dry organic matrix that fills the space between them (Fig. 4G, white arrows) and also permeates the aragonite crystals. Furthermore, a relatively thick layer of organic matrix is clearly visible contouring the upper edge of one of the crystals (Figs. 4G-H, white arrowheads) and partially filling the space between the two nacre tablets. It is interesting that even after prolonged etching at $-105^{\circ} \mathrm{C}$ the organic matrix layer did not dry as a network of fibers, but remained rather compact and solid in appearance. This suggests that the material differs from the space-filling material described above.

\section{Discussion}

We show that a hydrated protein phase is present at the site where the nacre tablets form. The outermost forming layer is enclosed by a sheet of organic material that is most probably the interlamellar organic matrix based on the presence of chitin and protein. We do not know whether this layer also corresponds to the thin organic film adhering to the growing mineral previously reported by Waller (1980) and others ([Marsh and Sass, 1983] and [Neff, 1972]). 
This layer separates the mantle cells/extrapallial fluid from the mineralization front, creating an enclosed space. Thus mineral formation takes place in a preformed compartment, consistent with the original observations of Bevelander and Nakahara (1969).

In light of previous observations that silk fibroin diffuses out of powdered shell suspended in water (Pereira-Mouries et al., 2002), it is reasonable to assume that the hydrated protein phase we observed in the ESEM and by cryo-SEM corresponds to the silk-like proteins. If so, our results corroborate the model of the structure of the nacre organic matrix proposed by LeviKalisman et al. (2001). Most important, our results show that nacre tablet formation does not occur in aqueous solution, but rather in a pre-formed hydrated gel-like medium.

The hydrophobic environment created by the silk-like proteins may play an important role in the regulation of the process of mineral formation. It has been demonstrated that these proteins are mild inhibitors of calcium carbonate crystallization (Cohen, 2003). It is therefore conceivable that one of their functions in vivo is to prevent uncontrolled crystallization, such that nucleation occurs only at the crystal nucleation site. Moreover, although the acidic proteins from the nacre are able to specifically induce aragonite formation, they are only capable of doing so in the presence of the silk-fibroin (Falini et al., 1996). This implies that the silk fibroin is essential for creating the appropriate microenvironment for other proteins to control polymorph type.

Our observations show that the tablets grow into the space occupied by the hydrogel phase. During their growth, they push aside and compress the space-filling material including the silk fibroin-like proteins, which becomes thinner until it is barely detectable between two layers of mature crystals. At this stage, it is possible that the silk-like proteins are under pressure and hence that is the reason why they spontaneously exude out of the fractured shell. The final state of the interlamellar matrix in the mature nacre, is of a layer of silk-like proteins sandwiched between the mineral and the chitin sheet (reviewed in Addadi et al. (2006). Interestingly, this final state corresponds to the model initially proposed by Weiner and Traub (1984) based on analyses of mature matrix sheets. They however inferred that the acidic macromolecules were located between the silk fibroin layer and the mineral surface. While the silk-like proteins are pushed ahead of the forming tablet, other organic matrix components, especially the more charged soluble macromolecules, are occluded inside the crystal to become the intra-crystalline phase ([Berman et al., 1993] and [Weiner and Addadi, 1997]). It is also conceivable that in P. margaritifera, which is known to have an intracrystalline organic matrix framework (Rousseau et al., 2005b), some of the silk-like proteins might also be incorporated in the intra-crystalline matrix. It should be noted that $A$. rigida and $P$. margaritifera belong to different taxonomic orders and are not closely related, and differences in their organic matrix structures may be present.

We could also visualize the dynamics of tablet formation and growth. The tablets are not fully formed in the most superficial layers (Fig. 3). The fractured tablets have irregular shapes, a rough appearance and variable thicknesses. Within 12 or so layers beneath the shell surface, the tablet fracture surface is very different (Figs. 4C-F), being smooth and regular. Thus, the process of tablet formation implies the need of a constant influx of calcium and carbonate ions to the growth front. It is difficult to envision a transport mechanism from the mantle tissue that can account for the observation that tablets continue to form several layers beneath the growing surface. It would be more likely that during formation of the topmost layer, all the calcium carbonate necessary for the formation of a single tablet is packed into the mineralization site as the organic matrix is assembled (Addadi et al., 2006). In that case, tablet 
formation from a supersaturated solution would be problematic in terms of the volume of solution necessary for providing all the ions, and in terms of the logistics of transporting sufficient mineral and removing large volumes of water (Addadi et al., 2006). It is possible that the formation of the precursor mineral phase occurs in another tissue and it is then transported to the mineralization site. Indeed, Neff (1972) observed mineral-containing granules in the apical cytoplasm and microvilli of the mantle cells, suggesting that they are transported to the mineralization front. An important question to address is whether or not mineral particles are also a major component of the pre-formed silk-like protein gel. Although we did not observe any, their absence might be due to the fact that the shells were stored in fixative solution prior to the experiment, and the mineral particles, if present, might have dissolved.

It is conceivable that the precursor mineral phase in nacre is in the form of amorphous calcium carbonate (ACC), as was observed in mollusk shell prismatic layer ([Nudelman et al., 2007] and [Politi et al., 2007]), in larval mollusk shells (Weiss et al., 2002) as well as in sea urchin larval spicule formation (Beniash et al., 1997). There is indirect evidence that such a strategy may account for nacre formation as well. Etched nacre tablets were shown to have a texture of 50-100 nm colloidal particles that is typical of crystals grown from amorphous precursors (Addadi et al., 2006). Moreover, a 3-5 nm ACC layer coating the surface of mature nacre tablets was reported (Nassif et al., 2005). We have also observed an unusual material phase between the forming tablet and the organic matrix (Figs. 4G-H, white arrowheads), which although composed mostly of organic material, is quite different from the separating interlamellar organic matrix (Figs. 4E-F, white arrowheads; G-H, white arrows). It is possible that this phase contains mineral that is being incorporated into the crystal in the form of ACC as well as macromolecules, and corresponds to the one observed by Nassif et al. (2005).

\section{Conclusions}

This is the first time that cryo-SEM is applied to the study of mollusk shell formation. We employed this technique to investigate the space between two interlamellar sheets, which is the site where the nacre tablets form, at the onset of mineralization. Our results show that the nacre tablets do not form in the presence of an aqueous solution, but in a hydrated gel-like medium. The ESEM and cryo-SEM results are consistent with this space-filling material being the silk-like proteins that create the appropriate microenvironment where the nacre tablets form.

\section{Acknowledgments}

We thank Dr. Derk Joester for his help on the ESEM work. We thank the society Tahiti Perles for financial and technical support. We thank the Minerva Foundation and the Kimmelman Center for Biomolecular Structure and Assembly, Weizmann Institute, and the Agence Nationale de la Recherche Francaise awards ANR Blan06-3_135480: Nacre Fluid, for financial support. L.A. is the incumbent of the Dorothy-and-Patrick-Gorman professorial chair of Biological Ultrastructure, and S.W. is the incumbent of the Dr. Trude Burchardt professorial chair of structural biology. 


\section{References}

Addadi et al., 2006 L. Addadi, D. Joester, F. Nudelman and S. Weiner, Mollusk shell formation: a source of new concepts for understanding biomineralization processes, Chem. Eur. J. 12 (2006), pp. 981-987.

Belcher et al., 1996 A.M. Belcher, X.H. Wu, R.J. Christensen, P.K. Hansma, G.D. Stucky and D.E. Morse, Control of crystal phase switching and orientation by soluble mollusc-shell proteins, Nature 381 (1996), pp. 56-58.

Beniash et al., 1997 E. Beniash, J. Aizenberg, L. Addadi and S. Weiner, Amorphous calcium carbonate transforms into calcite during sea-urchin larval spicule growth, Proc. R. Soc. Lond. B Ser. 264 (1997), pp. 461-465.

Berman et al., 1993 A. Berman, J. Hanson, L. Leiserowitz, T.F. Koetzle, S. Weiner and L. Addadi, Biological control of crystal texture: a widespread strategy for adapting crystal properties to function, Science 259 (1993), pp. 776-779.

Bevelander and Nakahara, 1969 G. Bevelander and H. Nakahara, An electron microscope study of the formation of the nacreous layer in the shell of certain bivalve molluscs, Calcif. Tissue Res. 3 (1969), pp. 84-92.

Cohen, 2003 Cohen, O., 2003. The influence of a gel environment on calcium carbonate biomineralization. M.Sc. thesis, Weizmann Institute of Science.

Crenshaw, 1972 M.A. Crenshaw, The soluble matrix of Mercenaria mercenaria shell, Biomineral. Res. Rep. 6 (1972), pp. 6-11.

Crenshaw and Ristedt, 1976 M.A. Crenshaw and H. Ristedt, The histochemical localization of reactive groups in septal nacre from Nautilus pompilius. In: N. Watabe and K.M. Wilbur, Editors, The Mechanisms of Mineralization in the Invertebrates and Plants, University of South Carolina Press, Colombia (1976), pp. 355-367.

Falini et al., 1996 G. Falini, S. Albeck, S. Weiner and L. Addadi, Control of aragonite or calcite polymorphism by mollusk shell macromolecules, Science 271 (1996), pp. 67-69. Gregoire, 1957 C. Gregoire, Topography of the organic components in mother-of-pearl, $J$. Biophys. Biochem. Cytol. 3 (1957), pp. 797-808.

Levi-Kalisman et al., 2001 Y. Levi-Kalisman, L. Addadi and S. Weiner, Structure of the nacreous organic matrix of a bivalve mollusk shell examined in the hydrated state using cryoTEM, J. Struct. Biol. 135 (2001), pp. 8-17.

Marin and Luquet, 2004 F. Marin and G. Luquet, Molluscan shell proteins, C.R. Palevol 3 (2004), pp. 469-492.

Marsh and Sass, 1983 M.E. Marsh and R.L. Sass, Calcium-binding phosphoprotein particles in the extrapallial fluid and innermost shell lamella of clams, J. Exp. Zool. 226 (1983), pp. 193-203

Nakahara, 1979 H. Nakahara, An electron microscope study of the growing surface of nacre in two gastropod species Turbo cornutus and Tegula pfeferi, Jpn. J. Malacol. 38 (1979), pp. 205-211.

Nassif et al., 2005 N. Nassif, N. Pinna, N. Gehrke, M. Antonietti, C. Jager and H. Colfen, Amorphous layer around aragonite platelets in nacre, Proc. Natl. Acad. Sci. USA 102 (2005), pp. 12653-12655.

Neff, 1972 J.M. Neff, Ultrastructure of the outer epithelium of the mantle in the clam Mercenaria mercenaria in relation to calcification of the shell, Tissue Cell 4 (1972), pp. 591600.

Nudelman et al., 2007 F. Nudelman, H.H. Chen, H.A. Goldberg, S. Weiner and L. Addadi, Lessons from biomineralization: comparing the growth strategies of mollusc shell prismatic and nacreous layers in Atrina rigida, Faraday Discuss. 136 (2007), pp. 9-25. 
Nudelman et al., 2006 F. Nudelman, B.A. Gotliv, L. Addadi and S. Weiner, Mollusk shell formation: mapping the distribution of organic matrix components underlying a single aragonitic tablet in nacre, J. Struct. Biol. 153 (2006), pp. 176-187.

Pereira-Mouries et al., 2002 L. Pereira-Mouries, M.J. Almeida, C. Ribeiro, J. Peduzzi, M. Barthelemy, C. Milet and E. Lopez, Soluble silk-like organic matrix in the nacreous layer of the bivalve Pinctada maxima, Eur. J. Biochem. 269 (2002), pp. 4994-5003.

Politi et al., 2004 Y. Politi, T. Arad, E. Klein, S. Weiner and L. Addadi, Sea urchin spine calcite forms via a transient amorphous calcium carbonate phase, Science 306 (2004), pp. 1161-1164.

Politi et al., 2007 Politi, Y., Mahamid, J., Goldberg, H.A., Weiner, S., Addadi, L., 2007. Asprich mollusk shell protein: in vitro experiments aimed at elucidating function in $\mathrm{CaCO} 3$ crystallization. Cryst. Eng. Commun. published online DOI: 10.1039/b709749b.

Rousseau et al., 2005a M. Rousseau, E. Lopez, A. Coute, G. Mascarel, D.C. Smith, R. Naslain and X. Bourrat, Sheet nacre growth mechanism: a Voronoi model, J. Struct. Biol. 149 (2005), pp. 149-157.

Rousseau et al., 2005b M. Rousseau, E. Lopez, P. Stempfle, M. Brendle, L. Franke, A. Guette, R. Naslain and X. Bourrat, Multiscale structure of sheet nacre, Biomaterials 26 (2005), pp. 6254-6262.

Sethmann et al., 2006 I. Sethmann, R. Hinrichs, G. Worheide and A. Putnis, Nano-cluster composite structure of calcitic sponge spicules - a case study of basic characteristics of biominerals, J. Inorg. Biochem. 100 (2006), pp. 88-96

Simkiss and Wilbur, 1989 K. Simkiss and K. Wilbur, Biomineralization, Cell Biol. Mineral Depos., Academic Press Inc., San Diego (1989).

Wada, 1972 K. Wada, Nucleation and growth of aragonite crystals in the nacre of some bivalve molluscs, Biomineralization 6 (1972), pp. 141-159.

Waller, 1980 T.R. Waller, Scanning electron microscopy of shell and mantle in the order Arcoida (Mollusca: Bivalvia) Smithsonian, Contrib. Zool. 313 (1980), pp. 1-58.

Watabe, 1965 N. Watabe, Studies on shell formation. XI Crystal-Matrix relationships in the inner layer of mollusk shells, J. Ultrastruct. Res. 12 (1965), pp. 351-370.

Weiner, 1979 S. Weiner, Aspartic acid-rich proteins: major components of the soluble organic matrix of mollusk shells, Calcified Tissue Int. 29 (1979), pp. 163-167.

Weiner and Addadi, 1997 S. Weiner and L. Addadi, Design strategies in mineralized biological materials, J. Mater. Chem. 7 (1997), pp. 689-702

Weiner et al., 1983 S. Weiner, Y. Talmon and W. Traub, Electron diffraction of mollusk shell organic matrices and their relationship to the mineral phase, Int. J. Biol. Macromol. 5 (1983), pp. 325-328.

Weiner and Traub, $1980 \mathrm{~S}$. Weiner and W. Traub, X-ray diffraction study of the insoluble organic matrix of mollusk shells, FEBS Lett. 111 (1980), pp. 311-316.

Weiner and Traub, 1984 S. Weiner and W. Traub, Macromolecules in mollusk shells and their functions in biomineralization, Phil. Trans. R. Soc. Lond. Ser. B 304 (1984), pp. 421-438.

Weiss et al., 2002 I.M. Weiss, N. Tuross, L. Addadi and S. Weiner, Mollusk larval shell formation: amorphous calcium carbonate is a precursor for aragonite, J. Exp. Zool. 293 (2002), pp. 478-491.

Wise, 1970 S.W. Wise, Microarchitecture and mode of formation of nacre (mother-of-pearl) in pelecypods, gastropods and cephalopods, Eclogae Geol. Helv. 63 (1970), pp. 775-797. 


\section{Figures}
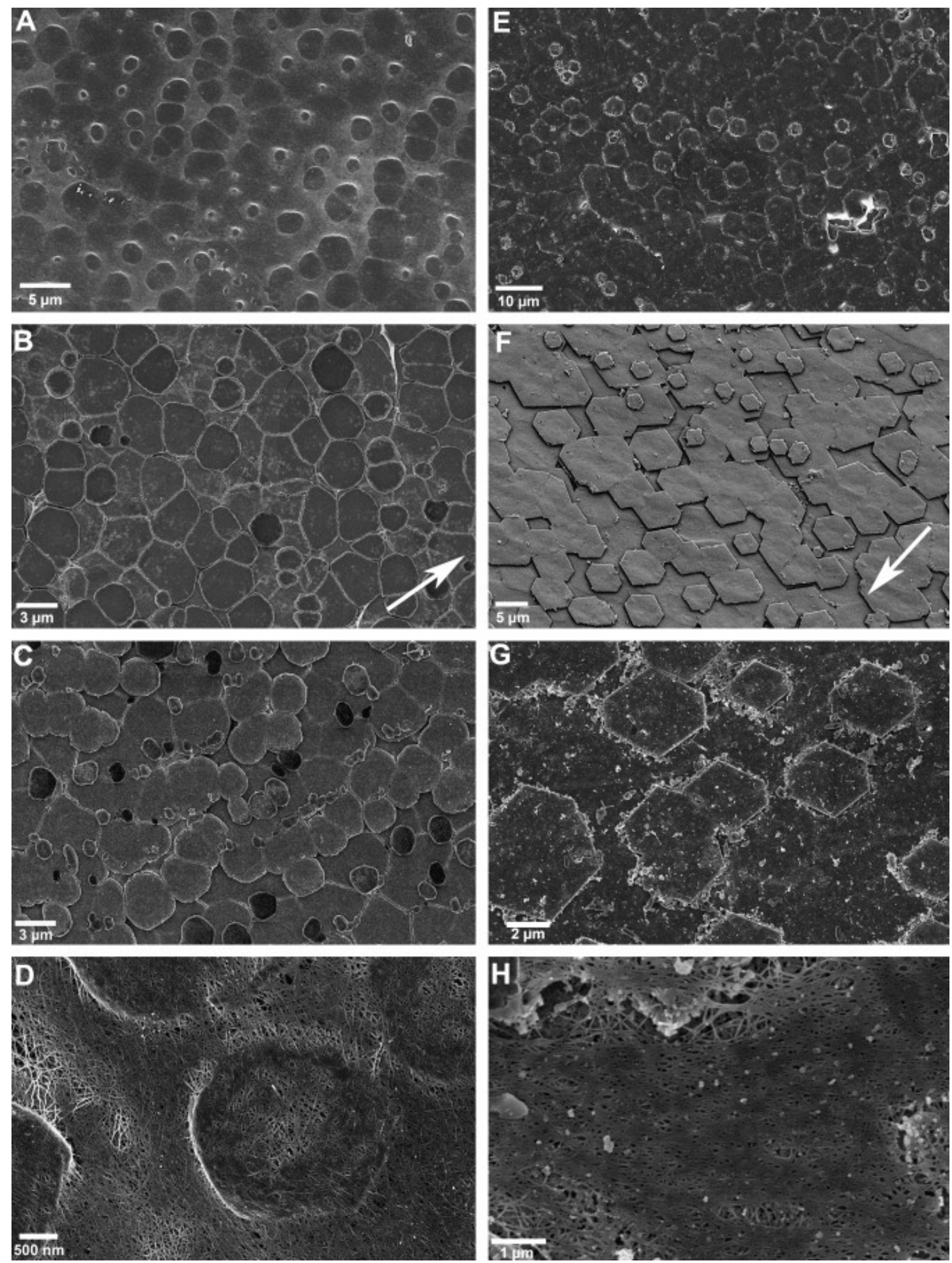

Fig. 1. SEM images of the growing nacre of Pinctada margaritifera (A-D) and Atrina rigida $(\mathrm{E}-\mathrm{H})$. (A and E) Growth front of the nacre, showing the growing aragonite crystals covered by a sheet of organic matrix. (B and F) Growth front after treatment with sodium hypochlorite, exposing the nacre tablets. Arrows point to the direction of growth. (C and G) Growth front of the nacre after treatment with chitinase. (D and H) Growth front of the nacre after treatment with proteinase K. Sample shown in A was plunged in liquid ethane and freeze-dried; samples in $(\mathrm{B}-\mathrm{H})$ were critical point dried. 

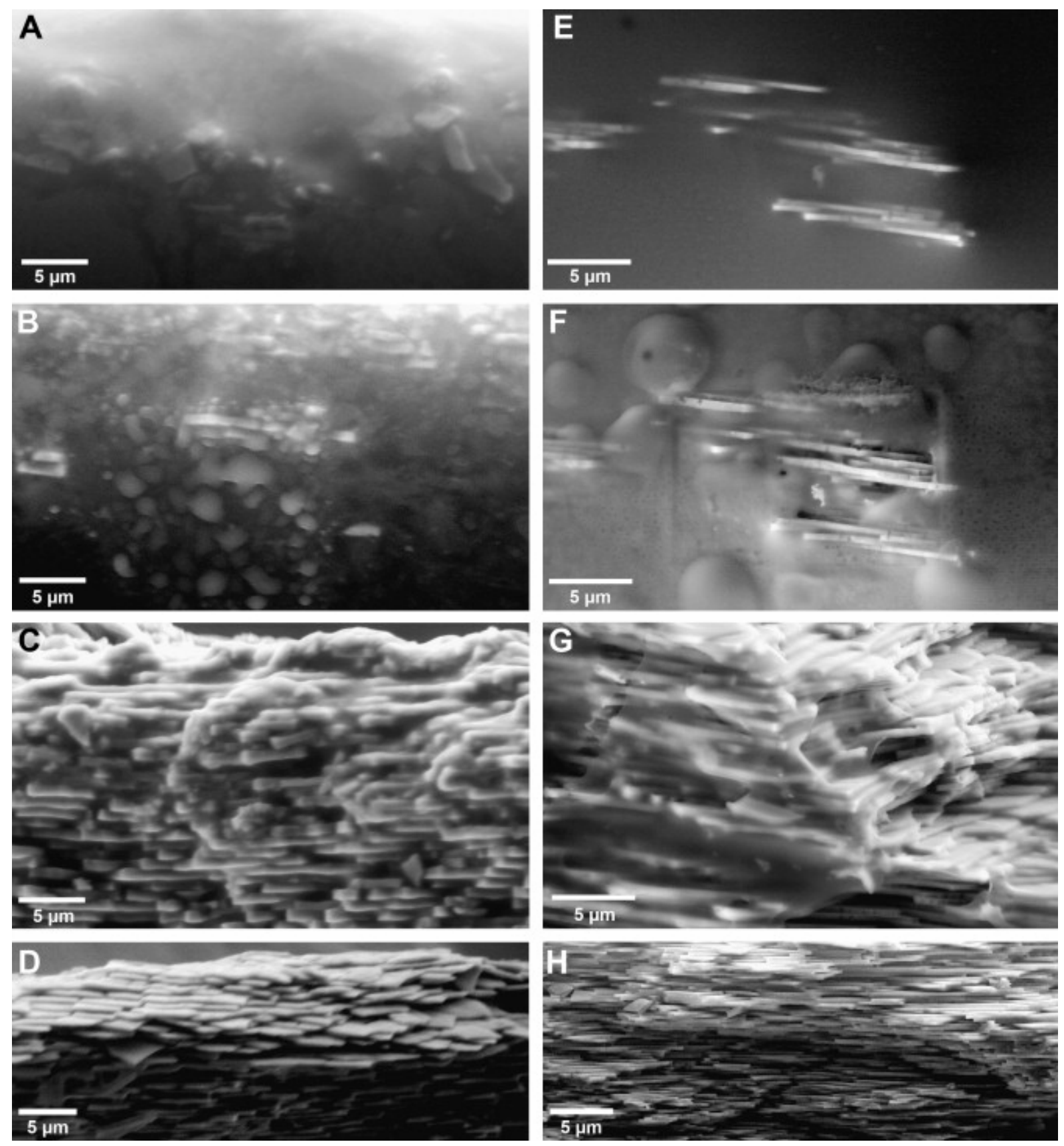

Fig. 2. Wet-mode environmental SEM (ESEM) images of fracture surfaces perpendicular to the lamina of fixed nacre of Pinctada margaritifera (A-D) and Atrina rigida (E-H). (A) Image taken after 60 min at 6 torr ( $92 \%$ humidity). (B) Image taken after subsequent 80 min with gradual decrease of pressure from 6 to 5.3 torr. (C) Image taken at 4.7 torr (72\% humidity). (D) Sample pre-treated with proteinase $\mathrm{K}$, observed using the same procedure as in (A) and (B). (E-G) Successive observations at constant pressure of 5.9 torr (90\% humidity). (E) Image taken after $60 \mathrm{~min}$ in the microscope. (F) Image taken after $65 \mathrm{~min}$. (G) Image taken after $70 \mathrm{~min}$, showing the sample completely dry. $(\mathrm{H})$ Sample pre-treated with proteinase K completely dry, observed after only $30 \mathrm{~min}$ in the microscope at 5.9 torr. 

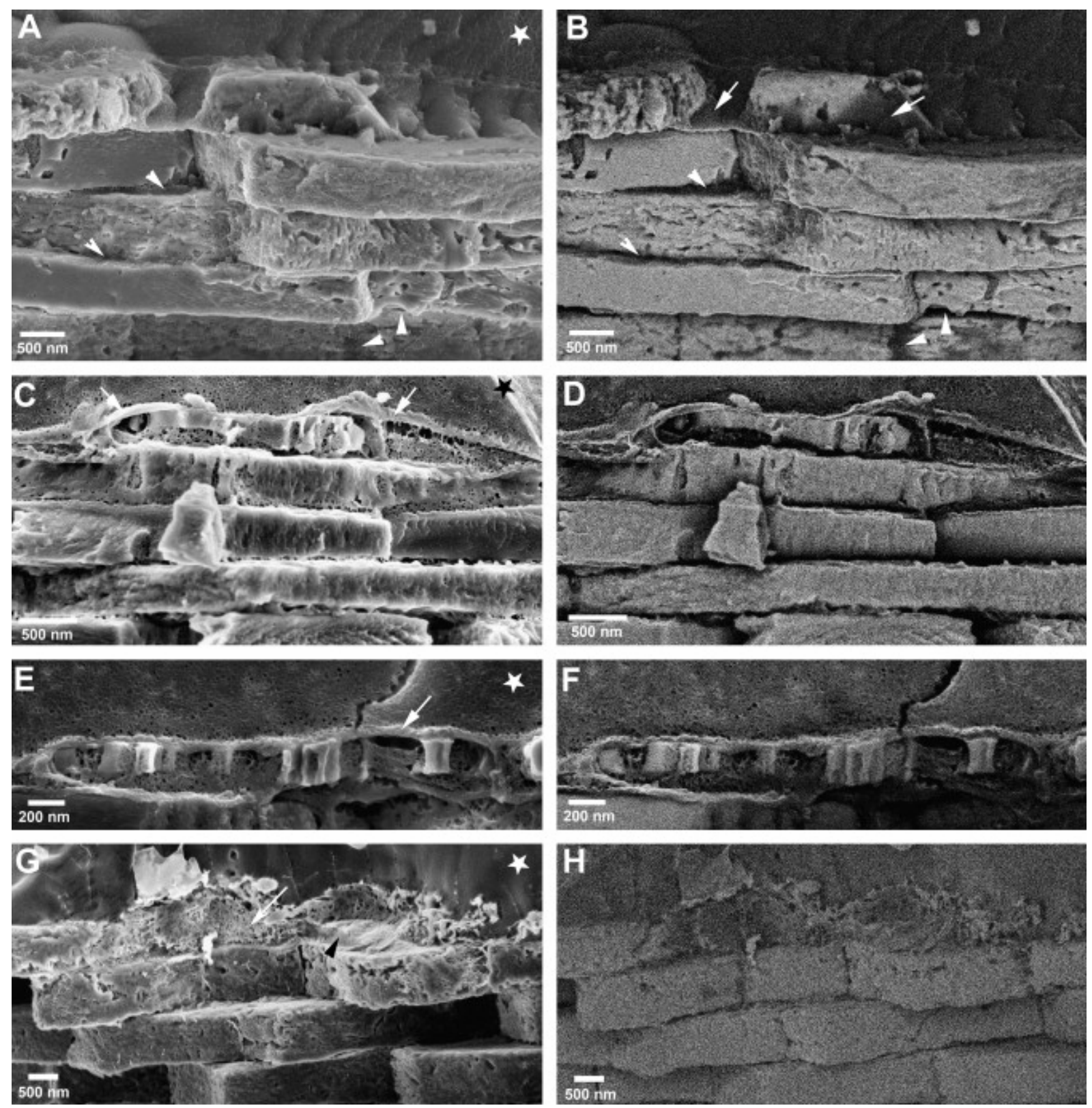

Fig. 3. Cryo-SEM images of a fracture surface of the nacre from the shell of Pinctada margaritifera. Samples were high-pressure frozen, fractured at $-120{ }^{\circ} \mathrm{C}$ and the ice was etched for either 5 or 20 min at $-105^{\circ} \mathrm{C}$. Left: In-lens secondary electrons images; right: In-lens backscattered electrons images. (A and B) Sample mounted in dextran (star) and etched for $5 \mathrm{~min}$. White arrowheads in A and B point to the organic matrix between the mineral lamina. White arrows in B point to organic material partly covering a growing crystal at the nacre surface. (C-F) Samples mounted in dextran (start) and dried for 20 min. White arrows point to the exposed interlamellar matrix. ( $\mathrm{G}$ and $\mathrm{H}$ ) Sample mounted in 1hexadecene (star) and dried for $5 \mathrm{~min}$. White arrow in G points to organic material at the topmost mineral layer; black arrowhead points to a growing crystal. 

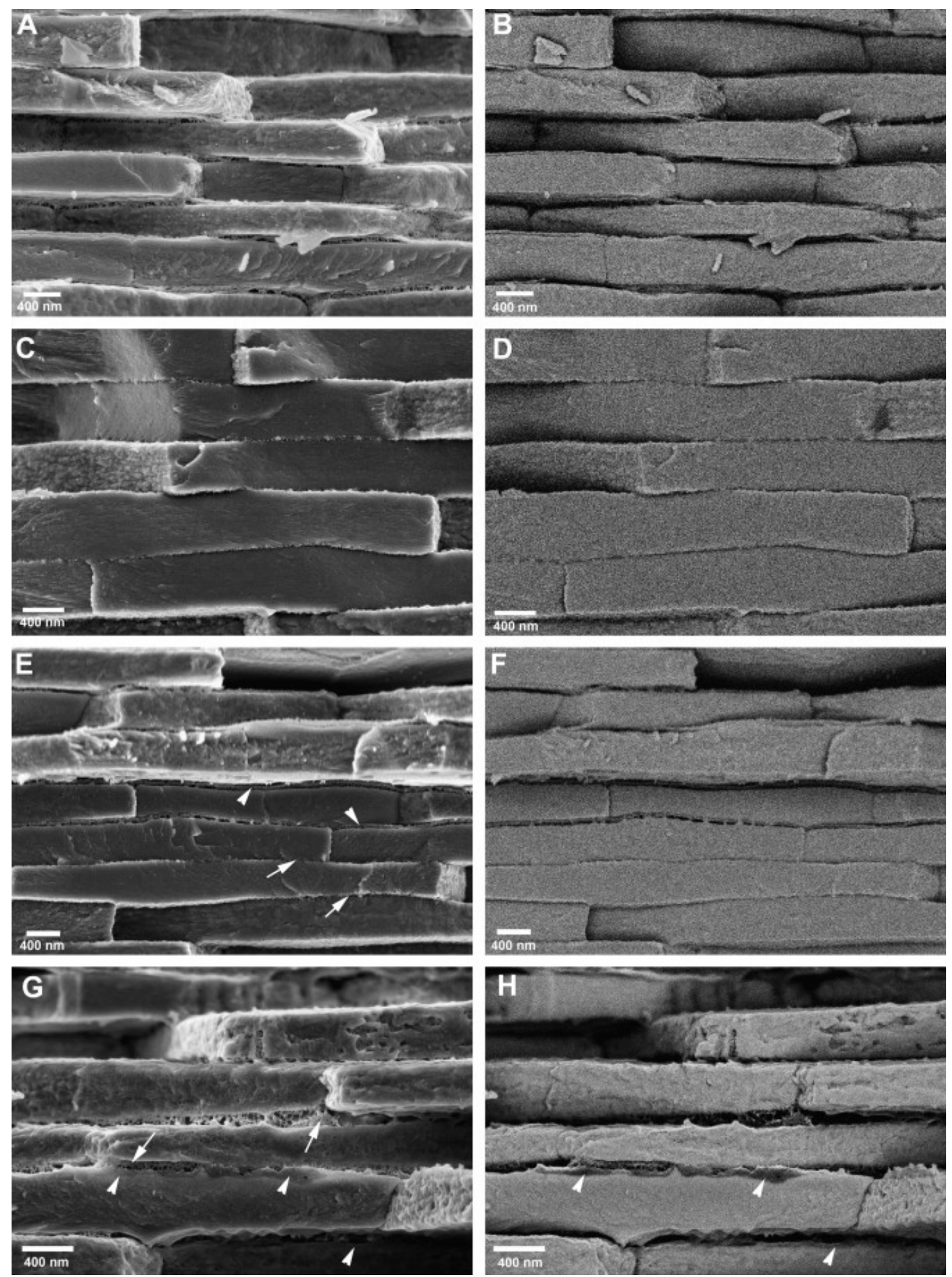

Fig. 4. Cryo-SEM images of a fracture surface of the nacre from the shell of Pinctada margaritifera. Samples were high-pressure frozen, fractured at $-120^{\circ} \mathrm{C}$ and the ice etched for $20 \mathrm{~min}$ at $-105^{\circ} \mathrm{C}$. Left: In-lens secondary electron images; right: In-lens backscattered electron images. (A and B) Image from the growth front (the 5 topmost layers). (C and D) Image from a mature region (15-20 layers below the nacre surface). ( $\mathrm{E}$ and $\mathrm{F}$ ) Image from a transition region, where the interlamellar matrix between the layers of mineral is visible only until a certain point (white arrowheads), after which the nacre tablets are in very close contact with each other (white arrows). ( $\mathrm{G}$ and $\mathrm{H}$ ) Image from the growth front (the 5 topmost layers). White arrows indicate a dry, network-like organic matrix and white arrowheads indicate a dry, compact organic material contouring a nacre crystal. 

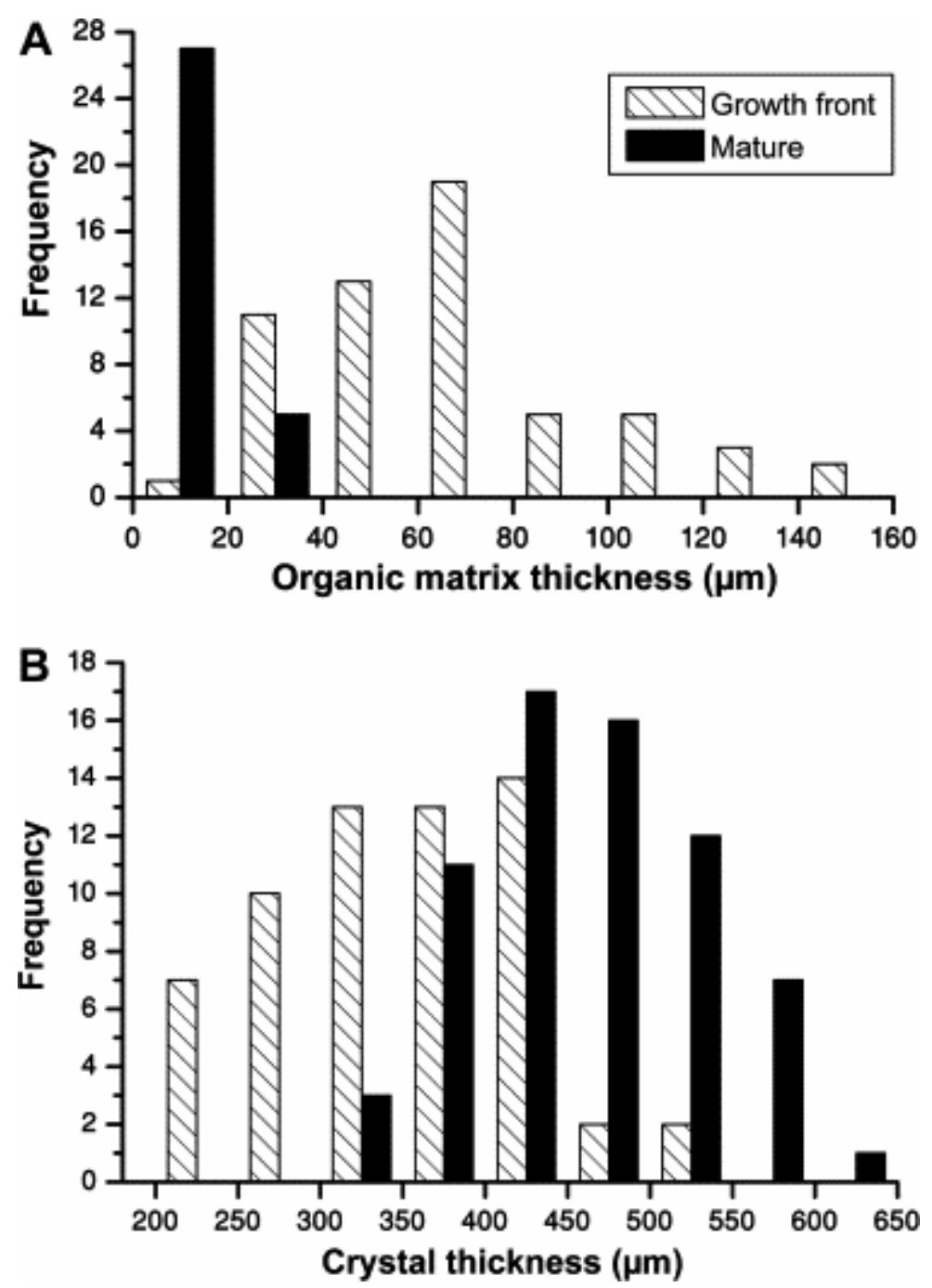

Fig. 5. Histogram of frequency distribution of the organic matrix (A) and tablet (B) thicknesses at the growth front and mature regions. (A) Growth front: $N=59$, average $\pm \mathrm{SD}=68 \pm 29 \mathrm{~nm}$; Mature region: $N=32$, average $\pm \mathrm{SD}=15 \pm 4 \mathrm{~nm}$. (B) Growth front: $N=61$, average $\pm \mathrm{SD}=350 \pm 73 \mathrm{~nm}$; Mature region: $N=67$, average $\pm \mathrm{SD}=460 \pm 68 \mathrm{~nm}$. 